\title{
A new method of accounting for runoff dams
}

\author{
$\underline{\text { R. Morden }}$ \\ Victorian Department of Environment Land Water and Planning \\ Email: robert.morden@delwp.vic.gov.au
}

\begin{abstract}
Runoff dams, sometimes called hillside dams or farm dams, are an essential part of agriculture in Australia, providing water for stock, domestic, and irrigation use. Runoff dams are typically very small at around $2 \mathrm{ML}$ on average, but can be smaller than $1 \mathrm{ML}$ or larger than $100 \mathrm{ML}$ depending on the climate, terrain, and intended purpose. Although each dam on average is relatively small, there are vast numbers of them across the country. One study estimated the total capacity of runoff dams in Australia in 2008 to be approximately 1460 GL (SKM/BRS 2010).
\end{abstract}

Modelling techniques to assess the impact of runoff dams on streamflow were first developed in Australia in the late 1990s, and have been progressively improved since then. Such modelling has primarily focussed on very local scales, such as the impact of all dams in a local catchment, or the impact of individual dams. Over time, there has been increasing recognition of the significance of runoff dams and their impact on surface water hydrology, which has led to an increasing need to formally account for their impact. For example, runoff dams have been included in the Victorian Water Accounts since 2003-04, and starting from 2019 runoff dams will be a key part of the Murray Darling Basin Plan (2012).

In comparison to methods used to estimate runoff dams at a local scale, most methods used to account for runoff dams at a basin or state scale are relatively simple and approximate. In many cases, the capacity of the dams multiplied by a nominal factor is assumed to be a reasonable proxy for their annual impact (SKM/BRS 2010), regardless of agriculture type or annual climate. In the past, this level of simplicity has been unavoidable for two key reasons:

- Lack of suitable data - to estimate impacts of runoff dams using current modelling techniques, an essential data requirement is surface runoff. While gauged streamflow data is easily available at small local scales, until recent times a complete set of such data has been virtually impossible to assemble for all areas across a region or jurisdiction. Modelling has been limited to local catchments where stream gauges exist.

- Difficulty in regionalisation - impacts of runoff dams seem to vary between wet and dry years, high and low levels of development, climate, and types of agriculture, often without any apparent rhyme or reason. Consistent patterns between catchments have been hard to identify.

This paper will outline a new method for accounting for runoff dams which overcomes these issues. It significantly reduces problems with data availability by only requiring digitised surface areas of all runoff dams and their spatial coordinates. All other data is based either on regional equations and relationships, or obtained directly from the Bureau of Meteorology's publicly available AWRA model outputs. Also, problems with regionalisation are completely avoided by directly calculating a water balance for every dam across a region. As with all hydrology, this method has significant inherent uncertainties, and more work is needed to characterise these.

Using an annual time step, this method allows for regional differences in agriculture type and climate, and can be aggregated at any scale from a small catchment to a large basin or entire state. Testing of the new method was undertaken on 11 small catchments across Victoria, with results indicating that it compares extremely well against more detailed daily models. With simple data inputs, simple calculations, and results which vary with climate, this method represents a practical approach to estimating impacts of runoff dams for accounting purposes.

Keywords: $\quad$ Runoff dams, farm dams, water accounting 


\section{INTRODUCTION}

Runoff dams, sometimes called hillside dams or farm dams, are an essential part of agriculture in Australia, providing water for stock, domestic, and irrigation use. They are typically very small at around 2 ML on average, but can be smaller than $1 \mathrm{ML}$ or larger than $100 \mathrm{ML}$ depending on a range of local factors. Although each dam on average is relatively small, there are vast numbers of them across the country. One study estimated the total capacity of runoff dams in Australia in 2008 to be approximately 1460 GL (SKM/BRS 2010).

To put the impact of runoff dams in context, it is estimated that there are approximately 700 GL of runoff dams in Victoria (SKM 2012), with an annual impact between $400 \mathrm{GL}$ and $1100 \mathrm{GL}$. This is broadly equivalent to the volume of water diverted for all urban and commercial purposes across Victoria, which is stated as $621 \mathrm{GL}$ in the 2014-15 Victorian Water Accounts (DELWP 2016).

Over time, there has been increasing recognition of the significance of runoff dams and their effect on surface water hydrology, which has led to an increasing need to formally account for their impact. For example, runoff dams have been included in the Victorian Water Accounts since 2003-04, and policy around understanding and limiting the impacts of runoff dams was a key element of the Northern, Western, and Gippsland Region Sustainable Water Strategies (DSE 2009, DSE 2011a, DSE 2011b). Also, runoff dams were explicitly recognised as a risk to water resources in the Murray Darling Basin (MDBC 2006). As a direct consequence, starting from 2019 accounting for impacts of runoff dams will be a key part of the Murray Darling Basin Plan (2012).

Modelling techniques to assess the impact of runoff dams on streamflow were first developed in Australia in the late 1990s, and have been progressively improved since then. Such modelling has primarily focussed on very local scales, such as the impact of all dams in a local catchment, or the impact and resource optimisation of individual dams. As existing modelling algorithms were focussed on this smaller local scale, they generally do not adapt well to water accounting problems which have a much broader spatial scale.

\section{EXISTING METHODS}

To date, methods used to estimate impacts of runoff dams at a local scale are based on moderately complex water balance algorithms. Examples of modelling tools include: STEDI (SKM 2011) and its forerunners TEDI and CHEAT, the farm dam plugin for eWater Source (Fowler et al 2012a) which is heavily based on the STEDI algorithm, and WaterCRESS (Cresswell and Clarke 2011). These methods can be data intensive, with dedicated software tools available. In comparison, most methods used to account for runoff dams at a basin or state scale have been relatively simple and approximate. For example:

- $\quad$ SKM/BRS (2010) assumed that a reasonable proxy for the long term average annual impact of a dam was the dam capacity multiplied by a nominal factor, regardless of climate or agriculture type.

- In the Victorian Water Accounts (DELWP 2016), the existing method is marginally more sophisticated, providing estimated impacts for "dry" or "average" years for each river basin across the state.

A more detailed method proposed by Srikanthan et al (2015) is available, and this is discussed in more detail in Section 3.

In the past, this level of simplicity has been unavoidable for two key reasons:

- Lack of suitable data - to estimate impacts of runoff dams using current modelling techniques, an essential data requirement is surface runoff. While gauged streamflow data is easily available at small local scales, until recent times a complete set of such data has been virtually impossible to assemble for all areas across a region or jurisdiction.

- Difficulty in regionalisation - While there is some consistency in characteristics of dams between regions, the impacts of dams defy regionalisation. Impacts seem to vary between wet and dry years, high and low levels of development, climate, and types of agriculture, often without any apparent rhyme or reason. While there is no specific literature on this subject, practitioners have observed that consistent patterns between catchments have been hard to identify.

Any new method of estimating runoff dam impacts for water accounting purposes will need to be conceptually robust, require easily available inputs, simple to run, and produce meaningful outputs at a regional scale. This paper proposes such a method. 


\section{CONCEPTUAL MODEL}

\subsection{Model basis}

The proposed method is based on the algorithm within the software package STEDI. As given in the STEDI user manual (SKM 2011), the algorithm is based on the following conceptual water balance.

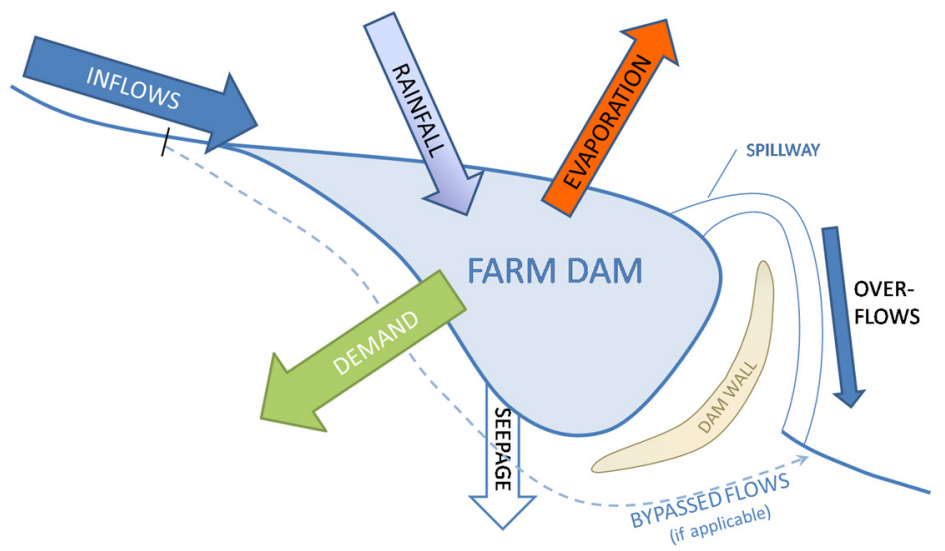

Figure 1. Conceptual water balance used in STEDI

Using this conceptual model, STEDI assumes that for each dam at each timestep (days, weeks, months):

$$
\begin{aligned}
& \triangle S T O R A G E=I N F L O W-B Y P A S S+R A I N-E V A P-D E M A N D-S E E P A G E-S P I L L \\
& I M P A C T=I N F L O W-B Y P A S S-S P I L L
\end{aligned}
$$

Some simplifications to these equations are justified when working at a regional scale. Firstly, summer flow bypasses on runoff dams are relatively uncommon, and secondly seepage is typically not modelled. These variables can be removed completely.

At this point, two practical observations can be introduced. Firstly, in wetter years a dam is likely to fill completely with some spills occurring. In this case the total volume of water stored does not vary significantly between years, and so the $\Delta$ STORAGE variable becomes zero. Skipping some algebraic steps, equations (1) and (2) can be combined as follows:

$$
I M P A C T=D E M A N D+E V A P-R A I N
$$

Secondly, in drier years there may not be enough inflow to fill the dam, and the dam never spills. In such years, it is possible to simplify equation (2) as follows:

$$
I M P A C T=I N F L O W
$$

There is no need to define a 'wet' or 'dry' year, instead this method adopts the lesser of equations (3) and (4). Essentially, this suggests that:

- in wetter years the annual impact of a dam on streamflow can be approximated as the sum of on-farm demands and climate on the surface of the dam; and

- in drier years the annual impact of a dam on streamflow can be approximated as the total inflow.

Importantly, equations (3) and (4) do not require spills or changes in storage to be calculated. These equations can also be represented graphically as shown in Figure 2.

These simplifications are important because they allow the calculations to be applied quickly and easily on a regional scale. Annual rainfall and evaporation are available for all of Australia from the Bureau of Meteorology, demand can be estimated as a function of dam capacity (Jacobs 2016), and new data products have recently become available which show surface runoff across Australia at annual, monthly, or daily timescales. If the capacity, surface area, and catchment area of each dam are known or can be estimated, then it becomes possible to estimate the impact of any dam regardless of location.

The farm dam accounting method proposed by Srikanthan et al (2015) is conceptually similar to that proposed here, involving the use of the STEDI algorithm given in equations (1) and (2) and using gridded runoff and climate inputs. The key differences are that calculation of storage 'memory' is no longer required for the method 


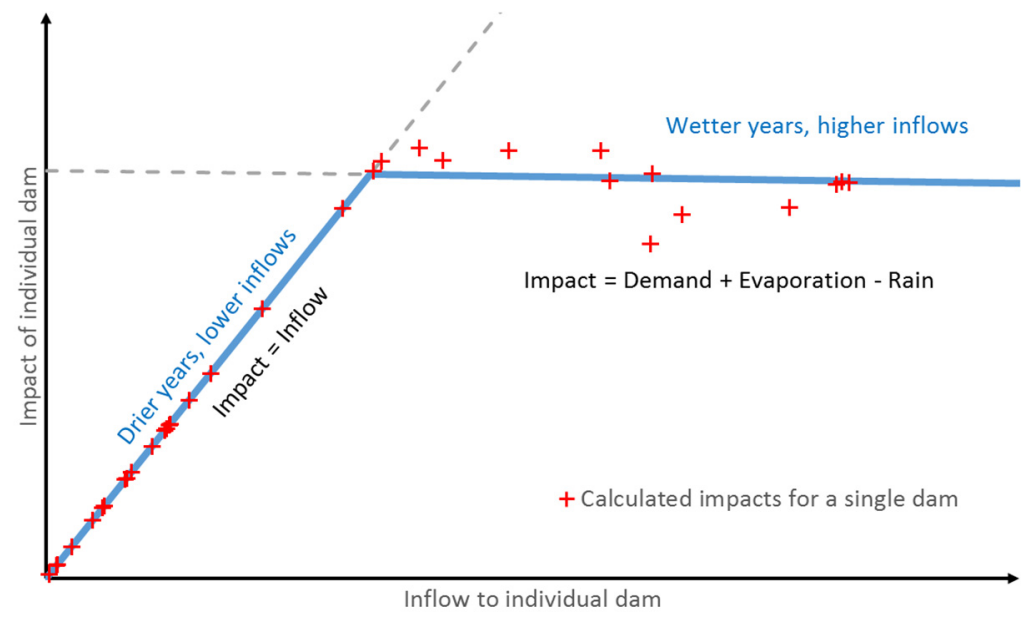

Figure 2. Estimating the annual impact of a single runoff dam - the solid line shows the conceptual model, the crosses show calculated impacts for a single dam using the new annual method

proposed in this paper, and the timestep is annual rather than monthly. In other words, the impact of a dam in any given year is a function of the aggregate climate and demand for that year, and is not affected by any previous years. This greatly reduces the complexity of calculations. The practical implication is that, for water accounting purposes, the model need only be run for a single year, reducing preparation and model run time.

\section{MODEL IMPLEMENTATION}

For testing purposes, the new method as described above was run for 11 small catchments across Victoria, covering a range of climate, streamflow, and land development situations. In total these 11 catchments included 3111 dams, and covered $1075 \mathrm{~km}^{2}$. Highly detailed models of each catchment were also prepared with STEDI on a daily timestep, including full details of all upstream catchment areas and connectivity between dams (HARC 2017). These STEDI models were created as a 'baseline' so that the efficacy of the new model could be evaluated. In other words, the STEDI models were assumed to be the most comprehensive and accurate model of runoff dam impacts, and were adopted as the 'observed' case, while the new annual model was adopted as the 'estimated' case.

Inputs to the new annual models and STEDI models were prepared as outlined in Table 1.

Table 1. Source data used in the models

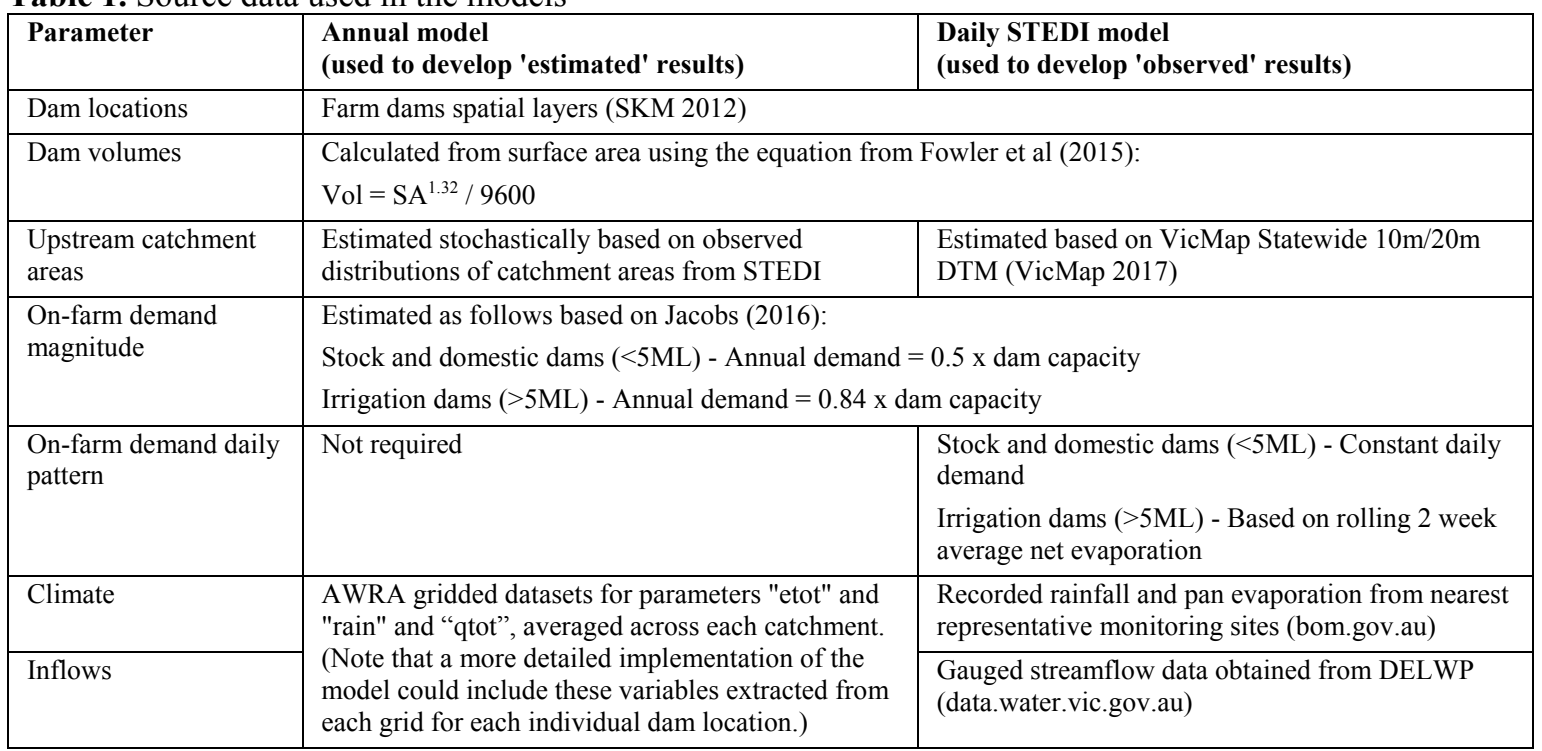


This new method significantly reduces problems with data availability. The only locally specific data required is digitised surface areas of all dams and their spatial coordinates. All other data is based either on established regional equations and relationships, or obtained directly from gridded spatial data.

Table 2 gives a brief summary of the hydrological characteristics of the 11 sample catchments.

Table 2. Characteristics of the 11 sample catchments

\begin{tabular}{|c|c|c|c|c|c|c|c|}
\hline Catchment & $\begin{array}{l}\text { Stream } \\
\text { gauge } \\
\text { number }\end{array}$ & $\begin{array}{r}\text { Area } \\
\left(\mathbf{k m}^{2}\right)\end{array}$ & $\begin{array}{c}\text { Number } \\
\text { of dams }\end{array}$ & $\begin{array}{r}\text { Volume } \\
\text { of dams } \\
\text { (ML) }\end{array}$ & $\begin{array}{r}\text { Volume } \\
\text { of dams } \\
\left(\mathbf{M L} / \mathbf{k m}^{2}\right)\end{array}$ & $\begin{array}{r}\text { Average } \\
\text { rainfall } \\
1980-2015 \\
(\mathrm{~mm} / \mathrm{yr})\end{array}$ & $\begin{array}{r}\text { Average } \\
\text { runoff } \\
1980-2015 \\
(\mathrm{~mm} / \mathrm{yr})\end{array}$ \\
\hline Combienbar River@ Combienbar & 221211 & 179 & 76 & 48 & 0.3 & 978 & 214 \\
\hline Franklin River@ Toora & 227237 & 75 & 269 & 237 & 3.2 & 1100 & 267 \\
\hline Woollen Creek@ @/S Of Bungal Dam & 232215 & 12 & 107 & 354 & 30 & 791 & 68 \\
\hline Love Creek@Gellibrand & 235234 & 75 & 179 & 281 & 3.7 & 954 & 228 \\
\hline Chetwynd River@ Chetwynd & 238229 & 69 & 255 & 236 & 3.4 & 651 & 28 \\
\hline Happy Valley Creek@ Rosewhite & 403214 & 135 & 257 & 1180 & 8.7 & 1162 & 350 \\
\hline Ford Creek@Mansfield & 405245 & 115 & 510 & 1462 & 13 & 857 & 149 \\
\hline Campaspe River@ Ashbourne & 406208 & 33 & 118 & 406 & 12 & 908 & 202 \\
\hline Mount Ida Creek@Derrinal & 406226 & 174 & 855 & 1334 & 7.7 & 622 & 60 \\
\hline Avoca River@ Amphitheatre & 408202 & 78 & 251 & 408 & 5.2 & 592 & 53 \\
\hline Richardson River@ Carrs Plains & 415226 & 130 & 234 & 331 & 2.5 & 473 & 9 \\
\hline
\end{tabular}

\section{TESTING PROCEDURE AND RESULTS}

To comprehensively test this new method, the first step was to compare the estimated dam impacts with the 'observed' dam impacts from STEDI using identical inputs. Subsequent comparisons were made, each time changing a single model input until all inputs were available at a broad regional scale. This process allowed some understanding of where changes to individual inputs make a significant difference to the outputs. For each run, the annual dam impacts were compared for all 3111 dams and for all years from 1980 to 2015. Figure 3 shows the results including $\mathrm{R}^{2}$ (square of the sample Pearson correlation coefficient), Nash Sutcliffe Efficiency (NSE), timeseries and scatter plots. The list of model runs is as follows:

1. All inputs identical to STEDI including locally recorded climate and streamflow data, and measured dam catchment areas

2. As for 1, but using rainfall and evaporation from AWRA

3. As for 2, but using runoff from AWRA

4. As for 3 , but using estimated dam catchment areas

\subsection{Discussion}

The results for Run 1 demonstrate that the new method provides meaningful results when using identical inputs to STEDI. As shown in Figure 3 below, the results show high $\mathrm{R}^{2}$ and NSE, which confirms that although the new method is based on an annual rather than daily timestep as for the STEDI models, relatively little information is lost when using such a large timestep.

The significant reduction in $\mathrm{R}^{2}$ and NSE between Run 2 and Run 3 highlight that the AWRA qtot variable is a key shortcoming of the new method. Further investigation suggests that in some locations AWRA runoff data does not accurately represent variability between years. For example, in the Richardson River catchment runoff rates in several higher flow years are recorded to be between $50 \mathrm{~mm}$ and $100 \mathrm{~mm}$, but the AWRA qtot variable averaged across this catchment never exceeds $41 \mathrm{~mm}$ in any year. Similarly in the Ford Creek catchment, runoff rates in some lower flow years are recorded to be below $10 \mathrm{~mm}$, but the AWRA qtot variable averaged across the catchment never drops below $40 \mathrm{~mm}$.

It is recognised that the qtot variable within AWRA is intended to represent surface runoff from a 1 dimensional grid cell prior to overland flow or stream routing processes, and as such is unlikely to accurately match recorded streamflow at a location further downstream. The observed discrepancies between recorded streamflow and the qtot variable are difficult to explain in terms of this conceptual difference.

Despite these shortcomings observed with the AWRA runoff data, it remains one of the few robustly developed runoff datasets available at a regional scale across Victoria. As such it is still the best available option for 
(a)
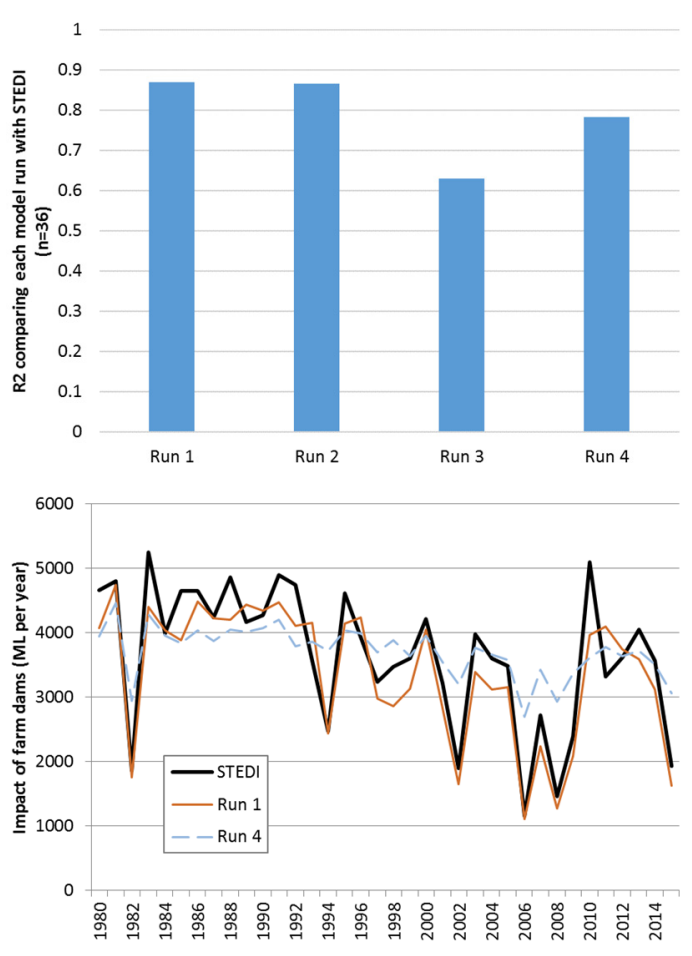

(c)

(b)
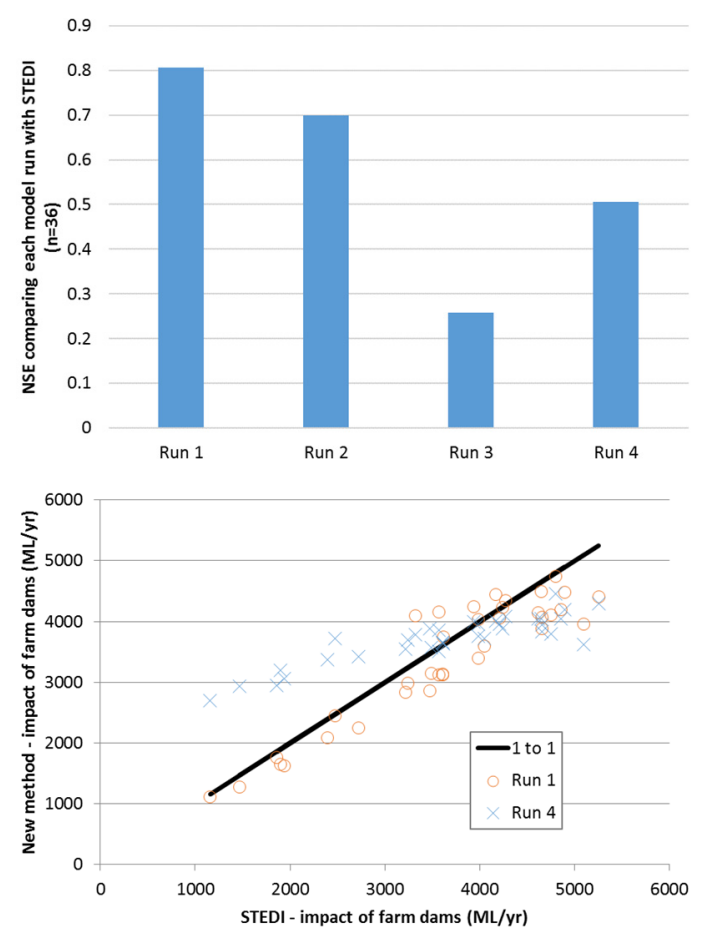

(d)

Figure 3. (a) $\mathrm{R}^{2}$ values for all model runs compared to STEDI (b) NSE values for all model runs compared to STEDI (c) time series of STEDI, Run 1, and Run 4 (d) Scatter plot showing observed vs estimated for

Run 1 and Run 4 (note that other runs were removed for clarity)

regional scale accounting applications. It is anticipated that as AWRA continues to be improved, the qtot variable will be improved too, making this method for estimating dam impacts more accurate in the process.

Run 4 represents the most simplified version of the new method, and is appropriate for regional scale accounting applications. The results show that this version of the model can still produce meaningful results.

It is important to note that Run 4 represents a model which can be quickly and easily applied to any location in Victoria. This is a significant step forward. In the past, runoff dam impacts could only be calculated for areas where a streamflow time series was available (as per run 1), providing a pattern of inflow to each dam. Model Run 4 does not use any local information other than the location and surface area of each dam, and can therefore provide estimated runoff dam impacts anywhere. All model runs also have the advantage that each timestep is fully independent. This has important time saving implications for water accounting purposes, where only a single timestep needs to be calculated for each year's accounts.

It is possible to make some further refinements to the conceptual model. In particular, it is possible to include some allowance for very dry years when dams do not completely fill. In subsequent wetter years, impacts may be slightly higher as the dams refill and recover from the dry period. This effect is relatively easy to implement and could be explored in future as a possible way to improve model accuracy from year to year.

It is important to note that these model runs can only provide a broad indication of how each change to the inputs or method affect outputs. To more definitively explore these issues, further testing of the model and its inputs needs to be undertaken. Several of the model inputs, such as on farm demand magnitude and pattern, are not accurately known and are based on industry established assumptions with considerable associated uncertainty. In addition, the stochastic approach to estimating catchment areas involves assigning areas at random using statistical distributions which were calibrated based on observed data. Given inputs with these uncertain and variable characteristics, a Monte Carlo study similar to Fowler et al (2015) would provide much clearer understanding of the efficacy of the model and the uncertainty associated with model results.

\section{CONCLUSIONS}

This paper has proposed a new method of estimating runoff dam impacts for water accounting purposes. Providing estimates of runoff dam impacts at an annual time step, this method allows for regional differences 
in agriculture type and annual climate, and can be aggregated at any scale from a small catchment with a handful of dams to a large basin or region with hundreds of thousands of dams.

The method is based on a simplified version of the algorithm used by STEDI which has been successfully applied to catchments across Victoria, South Australia, Western Australia, and the Murray Darling Basin. Using AWRA data for streamflow and climate inputs, the method requires relatively simple inputs which can be easily obtained for many locations across Australia. Testing of the new method indicates that it compares well against more detailed daily models, although quality of streamflow data appears to have a significant impact on the reliability of results.

Care needs to be taken when using this method, as many of the conceptual details such as on-farm demands, dam surface areas, seepage, and overland flow losses downstream of dams are poorly understood and have considerable uncertainty. Fowler et al (2015) showed that detailed STEDI modelling can estimate impacts with uncertainty of $\pm 24 \%$ at best. The uncertainty of this new method will be considerably greater, probably in excess of $\pm 50 \%$, perhaps more during very wet or very dry years. The implications of this uncertainty needs to be taken into account when deciding whether the method is fit for a given purpose.

With a robust conceptual basis, simple data inputs, simple calculations, and relatively accurate results, this method represents a practical approach to estimating impacts of runoff dams for accounting purposes. Further work is needed to better understand its limitations and its associated uncertainties.

\section{ACKNOWLEDGEMENTS}

The author would like to acknowledge Simon Lang and Dr Philip Jordan at Hydrology and Risk Consulting (HARC) for undertaking the detailed STEDI modelling of 11 catchments. Also, this work would not be possible without the excellent products created by the AWRA team at the Bureau of Meteorology. Lastly, the author would like to thank Dr Lisa Lowe and Geoff Steendam of DELWP for their reviews, patience, and good advice.

\section{REFERENCES}

Cresswell, D. and Clarke, R (2011). WaterCress User Manual, January 2011.

Department of Sustainability and Environment (2009). Northern Region Sustainable Water Strategy, State Government of Victoria, November 2009.

Department of Sustainability and Environment (2011a). Western Region Sustainable Water Strategy, State Government of Victoria, November 2011.

Department of Sustainability and Environment (2011b). Gippsland Region Sustainable Water Strategy, State Government of Victoria, November 2011.

Department of Environment Land Water and Planning (2016). Victorian Water Accounts 2014-2015, State Government of Victoria, October 2016.

Fowler, K., Donohue, R., Morden, R., Durrant, J., Hall, J., Narsey, S., Panosot, G., Breman, J. and O'Brien, D (2012a). Decision support using Source for licensing and planning in self supply irrigation areas. Proc. 15 th International River Symposium, Melbourne, October 2012.

Fowler, K., Morden, R., Lowe, L., and Nathan, R. (2015). Advances in assessing the impact of hillside farm dams on streamflow, Australian Journal of Water Resources 19 (2), 2015.

Hydrology and Risk Consulting (2017). Development of baseline farm dam models, Report prepared for Department of Environment, Land, Water, and Planning, February 2017

Jacobs (2016). Review of Demand Factors for Victorian Farm Dams, Report prepared for Department of Environment, Land, Water, and Planning, April 2016.

Murray-Darling Basin Commission (2006). Risks to the Shared Water Resources of the Murray-Darling Basin, MDBC Publication No. 22/06

Basin Plan (2012). Water Act 2007 (Cth) (Austl.)

Sinclair Knight Merz, CSIRO and BRS (2010). Surface and/or groundwater interception activities: initial estimates. Waterlines Report Series No 30 prepared for the National Water Commission, June 2010.

Sinclair Knight Merz (2011). STEDI: Estimating the impact of farm dams on streamflow: User Manual. Produced for the Department of Sustainability and Environment, Victoria, July 2011.

Sinclair Knight Merz (2012). Improving statewide estimates of farm dam numbers and impacts, Stage 3: State wide rollout report. Report prepared for the Department of Sustainability and Environment, Victoria, February 2012.

R. Srikanthan, S. Barua and M. Hafeez (2015). Estimating Volume of Water Harvested by Farm Dams in Murray-Darling Basin, Proc. $21^{\text {st }}$ International Congress on Modelling and Simulation, December 2015.

VicMap (2017). Statewide 10m/20m DTM, Anzlic Id ANZVI0803003582, State Government of Victoria. 